\title{
Comparative test of two large solar collectors for solar field application
}

\author{
Bava, Federico; Furbo, Simon
}

Published in:

Proceedings of EuroSun 2014

Publication date:

2014

Link back to DTU Orbit

Citation (APA):

Bava, F., \& Furbo, S. (2014). Comparative test of two large solar collectors for solar field application. In Proceedings of EuroSun 2014

\section{General rights}

Copyright and moral rights for the publications made accessible in the public portal are retained by the authors and/or other copyright owners and it is a condition of accessing publications that users recognise and abide by the legal requirements associated with these rights.

- Users may download and print one copy of any publication from the public portal for the purpose of private study or research.

- You may not further distribute the material or use it for any profit-making activity or commercial gain

- You may freely distribute the URL identifying the publication in the public portal

If you believe that this document breaches copyright please contact us providing details, and we will remove access to the work immediately and investigate your claim 


\title{
Conference Proceedings
}

EuroSun 2014

\section{COMPARATIVE TEST OF TWO LARGE SOLAR COLLECTORS FOR SOLAR FIELD APPLICATION}

\author{
Federico Bava ${ }^{1}$ and Simon Furbo ${ }^{1}$ \\ ${ }^{1}$ DTU Civil Engineering, Technical University of Denmark, Brovej, Building 118, 2800 Kgs. Lyngby (Denmark)
}

\begin{abstract}
Two large solar collectors for solar heating plants were tested according to the standard norm EN 12975-2. The two collectors were almost identical, the only difference being a thin FEP (fluorinated ethylene propylene) foil interposed between the absorber and the glass cover in one of them, in order to decrease convection losses. The efficiencies of the collectors were tested for different flow rates and tilt angles. The effect of the change from laminar to turbulent regime was investigated as well. Numerical models of the two collectors were developed with the software Soleff and their results were compared to the experimental measurements. The experimental results showed that the FEP foil caused a decrease in the start efficiency of 2-4 percent. Nevertheless, the collector with the FEP foil performed better when the mean temperature of the solar collector fluid was sufficiently high. Additionally, the collector efficiency of both collectors increased at higher flow rates and tilt angles. The models developed in Soleff fit the experimental results with an average error of $1 \%$ in case of fully laminar and turbulent flow, so that they are likely to be suitable to simulate the collector performances in untested conditions. On the other hand, the software proved to be inadequate to study the collector efficiency in the transition region between laminar and turbulent regime.
\end{abstract}

Keywords: solar collector, solar heating plant, efficiency, tilt angle, flow rate, flow regime, FEP, Soleff

\section{Introduction}

By the end of 2013 Denmark had already installed almost 400,000 square meters of thermal collectors for solar heating plants, while another 350,000 square meters were to be built in the near future (Windeleff and Nielsen, 2014; Furbo et al., 2014). In a scenario still characterized by strong growth in the installed solar collectors' capacity, even an efficiency improvement of few percent would lead to a large increase in the overall energy production in absolute terms. For this reason, knowing in which conditions a collector performs best is of key importance. Nevertheless, the technical specification sheets released by collector manufacturers usually state the collector efficiency only for one operating condition, which can differ significantly from those actually used in solar plant applications, so the actual thermal performance of the collector cannot be known in advance. This study focused on an experimental test of two large solar collectors (models HT-SA 35-10 and HT-A 35-10), produced by the Danish company ARCON Solar A/S. The only difference between the two collectors was the presence of a FEP (fluorinated ethylene propylene) foil interposed between the absorbing plate and the glass cover in the model HT-SA only. The presence of the FEP foil reduces the convection losses, as the air between absorber and glass circulates in two different layers of convective cells, one above and the other below the foil. The heat losses from the collector cover are therefore lower than in the collector without foil, due to the additional thermal resistance given by the convective heat transfer coefficient between air and FEP foil. On the other hand, as the foil is not completely transparent, it slightly reduces the solar irradiance reaching the absorber. Consequently, there is a certain temperature below which the collector without foil performs better than the other, as the transmittance of the cover plays a more significant role than the thermal losses.

The technical specification sheets (Arcon Solar, 2010; SP Technical Research Institute of Sweden, 2011) state the collector efficiency when a $25\left(\right.$ litres $\mathrm{min}^{-1}$ ) flow rate of pure water is supplied to a $60^{\circ}$ tilted 
collector, conditions which are very unlikely to be found in a Danish solar collector field. For this reason, the two collectors were tested at different flow rates and tilt angles, using a mixture of propylene glycol and water with a mass concentration of $40 \%$. In fact, the efficiency of a solar collector is influenced by the volume flow rate, as shown by Chiou (1982) and Wang and Wu (1990) for vertical pipe collectors and by Fan and Furbo (2008) for horizontal pipe collectors. The influence of the tilt on collector efficiency was investigated by Furbo and Holck (1995).

The experimental determination of the collector efficiency equation is of key importance when assessing the actual performance of the collectors in certain operating conditions. As experimental tests are usually time consuming and expensive, it may be useful to have a model that is able to estimate the collector efficiency, so that it can be used to predict its value also in conditions that differ from those tested. In this study, such a model was created in Soleff, software developed at Technical University of Denmark (Rasmussen and Svendsen, 1996), and compared to the experimental measurements.

\section{Materials and method}

\subsection{Experimental part}

The two investigated solar collectors were manufactured by the Danish company ARCON Solar A/S. More specifically they were the models HT-SA 35-10 and HT-A 35-10. The collectors were largely identical in terms of design and technical specifications and the only relevant difference was a $0.025 \mathrm{~mm}$ thick FEP foil. The different appearance of the two collectors can be seen in Fig. 1.

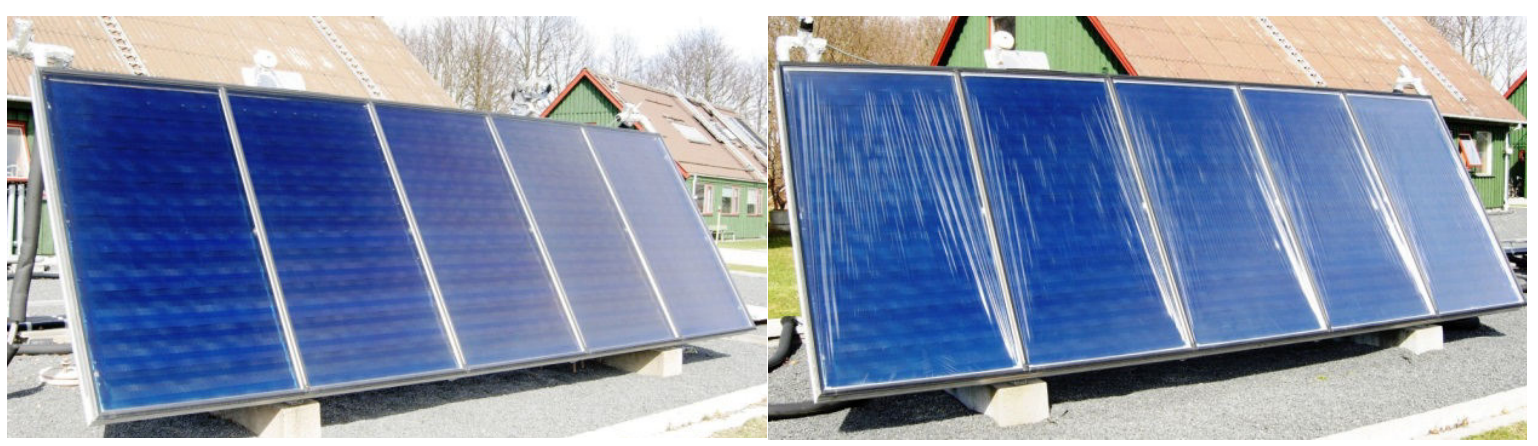

Fig. 1: Solar collector HT-A 35-10 (left) and HT-SA 35-10 (right) at the Department of Civil Engineering at the Technical University of Denmark.

The collectors were installed beside each other, so that they experienced identical weather conditions. They both had an orientation of $9.5^{\circ}$ West with respect to South, while the tilt angle could be changed through the use of semi-mobile scaffolding. Both collectors had external dimensions of $2.27 \times 5.96 \times 0.14 \mathrm{~m}$ with a total gross area of $13.57 \mathrm{~m}^{2}$, while the aperture area was equal to $12.56 \mathrm{~m}^{2}$. The absorber consisted of 18 aluminium strips covered by a selective coating. Each collector had two manifolds with a diameter of 35 $\mathrm{mm}$, placed vertically along the sides and connected by 18 horizontal copper tubes with a diameter of 10 $\mathrm{mm}$, laser-welded below the absorber strips. The external cover was made of an anti-reflective treated glass with a thickness of $3.2 \mathrm{~mm}$. The insulation consisted of mineral wool, with a thickness of $75 \mathrm{~mm}$ below and $30 \mathrm{~mm}$ along the edges. The stated efficiencies, based on the aperture area and using a pure water flow of 25 (litres $\mathrm{min}^{-1}$ ) and a $60^{\circ}$ tilt angle, are given by the equations (Eq.1) and (Eq.2) for the model HT-A and HTSA respectively (Arcon Solar, 2010; SP Technical Research Institute of Sweden, 2011).

$$
\begin{aligned}
& \eta_{H T-A, 60^{\circ}, 25}=0.845-2.94 \cdot \frac{T_{m}-T_{a}}{G}-0.013 \cdot \frac{\left(T_{m}-T_{a}\right)^{2}}{G} \\
& \eta_{H T-S A, 60^{\circ}, 25}=0.827-1.18 \cdot \frac{T_{m}-T_{a}}{G}-0.032 \cdot \frac{\left(T_{m}-T_{a}\right)^{2}}{G}
\end{aligned}
$$

where $\quad \eta[-]$ is the collector efficiency,

$T_{m}\left[{ }^{\circ} \mathrm{C}\right]$ is the mean fluid temperature inside the collector,

$T_{a}\left[{ }^{\circ} \mathrm{C}\right]$ is the ambient temperature, 
$G\left[\mathrm{~W} \mathrm{~m}^{-2}\right]$ is the global solar irradiance on the collector plane,

the subscripts of $\eta$ have the following meaning: HT-A/HT-SA refer to the collector model; the first numerical subscript denotes the tilt angle (in degrees), while the second numerical subscript the flow rate (in litres per minute).

The solar collectors were installed and tested in a solar collector test facility at the Technical University of Denmark. The fluid flow rates to the collectors were measured by two electromagnetic flow meters manufactured by Kamstrup (model MP240 and MP115 for the collector HT-A and HT-SA respectively). The inlet temperatures were measured by type TT thermocouples using a copper-constantan junction, while the temperature differences between outlet and inlet temperature were measured by thermopiles with five copper-constantan junctions at each measuring point. The total radiation on the collector plane was measured independently for each collector by a CM11 pyranometer, produced by Kipp \& Zonen and fully compliant with the norm ISO 9060, while the diffuse radiation was measured by a similar pyranometer equipped with a shadow band.

The collectors were tested with a tilt angle of $45^{\circ}$ at 5,10 and 25 (litres $\min ^{-1}$ ) between 2011 and 2012, and then with tilt angles of $30^{\circ}$ and $60^{\circ}$ at 25 (litres $\mathrm{min}^{-1}$ ) in 2013, using a propylene glycol/water mixture with a $40 \%$ weight concentration as solar collector fluid. The collector efficiency expressions were evaluated according to the standard norm EN 12975-2, so at least four independent data points were obtained for at least four different temperature levels, in a range between $20^{\circ} \mathrm{C}$ and $100{ }^{\circ} \mathrm{C}$. These data points were then interpolated by means of regression according to the method of least squares.

As different flow rates and temperature levels might cause changes in flow regime and therefore affect the heat transfer between absorber and solar collector fluid, pressure drop tests were performed on the HT-SA collector in 2014, in order to identify in which range of Reynolds numbers the transition from laminar to turbulent regime occurred. Such tests were carried out using a TA-SCOPE differential pressure sensor, manufactured by TA Hydronics, and supplying the collector with water at approximately $20-30{ }^{\circ} \mathrm{C}$ and varying the flow rate between 10 and $30\left(\right.$ litres $\left.\min ^{-1}\right)$. As the pressure drop measurements were taken at the inlet and outlet of the collector, the contribution given by the inlet/outlet connections and manifolds needed to be estimated and subtracted, in order to identify the pressure drop due to the horizontal pipes only. The pressure drops given by inlet/outlet connections and manifolds were evaluated using correlations found in literature (Idelchik, 1994). When the pressure drop across the horizontal pipes was isolated, the Darcy friction factor was evaluated according to (Eq.3).

$$
f=\frac{2 D \cdot \Delta p}{L \cdot \rho \cdot w^{2}} \quad(\text { Eq.3) }
$$

where $f[-]$ is the Darcy friction factor,

$D[\mathrm{~m}]$ is the inner diameter of the horizontal pipe,

$\Delta p[\mathrm{~Pa}]$ is the pressure drop across the horizontal pipe,

$L[\mathrm{~m}]$ is the length of the horizontal pipe,

$\rho\left[\mathrm{kg} \mathrm{m}^{-3}\right]$ is the fluid density evaluated at the mean fluid temperature across the collector,

$w\left[\mathrm{~m} \mathrm{~s}^{-1}\right]$ is the mean fluid velocity in the horizontal pipe.

The incidence angle modifier was evaluated according to the test procedure suggested in the norm EN 12975-2, but the tangent formula (Eq.4) was used in place of the cosine formula, as the former proved to fit the experimental data more accurately than the latter.

$$
I A M=1-\tan ^{p}\left(\frac{\Theta}{2}\right)
$$

where $\Theta\left[{ }^{\circ}\right]$ is the angle of incidence,

$$
p[-] \text { is the characteristic coefficient. }
$$




\subsection{Soleff simulation}

The calculation of the experimental efficiency curves is of key importance to assess the actual performance of the collectors under given operating conditions. It could be both interesting and useful to have a model able to evaluate the collector efficiency also in conditions that differ from those tested. Such models were created using Soleff, a solar collector simulation software developed at Technical University of Denmark (Rasmussen and Svendsen, 1996).

Soleff requires a large number of input parameters, ranging from design characteristics of the collector to operating and weather conditions. Regarding the weather conditions, measured data were used whenever available. The earth radiation temperature and the sky temperature were assumed equal to the ambient temperature and to the ambient temperature decreased by $20 \mathrm{~K}$ respectively. Most of the collector characteristics were found either in the collector datasheets or in literature (Rasmussen and Svendsen, 1996; Furbo and Shah, 2003). Input parameters for which the exact value could not be found were assumed according to common values found in literature and iteratively modified in order to obtain the best fit with the experimental data.

Despite the large number of different aspects which is considered by Soleff, this software cannot take into account the complexity of the real-world operation. For example, the software assumes uniform flow distribution in the different pipes, constant fluid properties across the collector and sudden change from laminar to turbulent flow regime at a Reynolds number $(R e)$ of approximately 2200 . The last one proved to be the less accurate simplification, as measured efficiencies obtained for Reynolds numbers between 2200 and 2400 were always lower than those computed by the Soleff models (which assumes turbulent regime in this range). Then, increasing slightly the pipe diameter in the simulation models, the flow was forced to be laminar and the efficiency in this case was calculated. So, the experimental results could be compared to those returned by the simulation models, in both cases where turbulent and laminar flow was assumed.

\section{Results}

\subsection{Experimental part}

Based on the experimental results and according to the standard norm EN 12975-2, the following efficiency expressions were obtained:

$$
\begin{aligned}
& \eta_{H T-A, 45^{\circ}, 5}=0.835-3.13 \cdot \frac{T_{m}-T_{a}}{G}-0.0143 \cdot \frac{\left(T_{m}-T_{a}\right)^{2}}{G} \\
& \eta_{H T-S A, 45^{\circ}, 5}=0.818-2.76 \cdot \frac{T_{m}-T_{a}}{G}-0.0096 \cdot \frac{\left(T_{m}-T_{a}\right)^{2}}{G} \\
& \eta_{H T-A, 45^{\circ}, 10}=0.843-3.55 \cdot \frac{T_{m}-T_{a}}{G}-0.0070 \cdot \frac{\left(T_{m}-T_{a}\right)^{2}}{G} \\
& \eta_{H T-S A, 45^{\circ}, 10}=0.804-2.26 \cdot \frac{T_{m}-T_{a}}{G}-0.0107 \cdot \frac{\left(T_{m}-T_{a}\right)^{2}}{G} \\
& \eta_{H T-A, 45^{\circ}, 25}=0.845-3.80 \cdot \frac{T_{m}-T_{a}}{G} \\
& \eta_{H T-S A, 45^{\circ}, 25}=0.810-2.83 \cdot \frac{T_{m}-T_{a}}{G} \\
& \eta_{H T-A, 60^{\circ}, 25}=0.850-3.71 \cdot \frac{T_{m}-T_{a}}{G} \\
& \eta_{H T-S A, 60^{\circ}, 25}=0.806-2.74 \cdot \frac{T_{m}-T_{a}}{G} \\
& \eta_{H T-A, 30^{\circ}, 25}=0.832-4.04 \cdot \frac{T_{m}-T_{a}}{G} \\
& \eta_{H T-S A, 30^{\circ}, 25}=0.805-3.13 \cdot \frac{T_{m}-T_{a}}{G} \\
& G \begin{array}{l}
G \\
G
\end{array}
\end{aligned}
$$


The efficiency curves (Eq.5)-(Eq.14) can be seen in Fig. 2 (constant tilt angle and variable flow rate) and Fig. 3 (constant flow rate and variable tilt angle). Comparing the different efficiency equations, it can be noted that the zero-loss efficiency was mainly independent of both flow rate and tilt angle. However, it was strongly influenced by the presence of the FEP foil, which caused a decrease of between 2 and 4 percent. Nevertheless, the presence of the foil reduced the heat losses by approximately $0.6-1.1 \mathrm{~W} \mathrm{~m}^{-2} \mathrm{~K}^{-1}$, so that for temperatures higher than a specific value (which can be defined as intersection reduced temperature), the HT-SA collector performed better than the HT-A model.

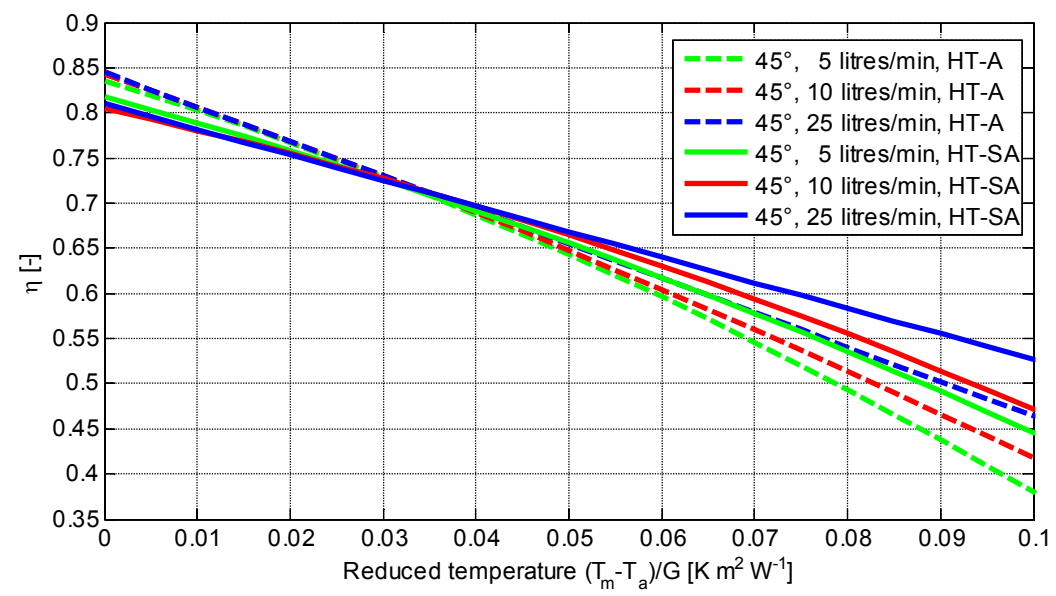

Fig. 2: Efficiency curves at different flow rates for the $\mathbf{H T}$ collectors at $45^{\circ}$ tilt and for a total solar irradiance $\mathrm{G}=1000 \mathrm{~W}^{-2}$.

As Fig. 2 shows, the larger the flow rate was, the higher the efficiency. The difference in efficiency between 5 and 10 (litres $\mathrm{min}^{-1}$ ) flow rates and the 25 (litres $\mathrm{min}^{-1}$ ) case became more significant at high temperatures, because of the presence of the second order heat loss coefficient, which was missing in the efficiency expressions for 25 (litres $\left.\mathrm{min}^{-1}\right)$.

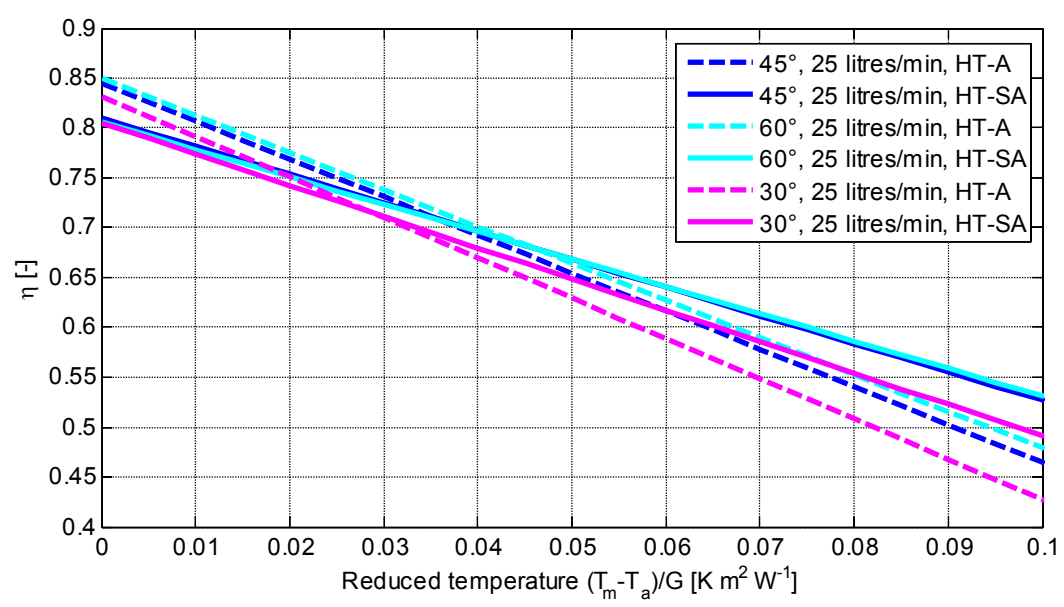

Fig. 3: Efficiencies curves at different tilts for the HT collectors at 25 (litres min $^{-1}$ ).

From Fig. 3, it may be seen that the larger the tilt angle, the higher the efficiency. Nevertheless, the relation between tilt angle and efficiency was not linear for either of the collectors. In fact, taking $45^{\circ}$ tilt as a reference, decreasing the angle to $30^{\circ}(-33 \%)$ caused an increase in the first order heat loss coefficient by about $10 \%$, while a tilt of $60^{\circ}(+33 \%)$ caused the same coefficient to decrease by only about $3 \%$. In fact, in Fig. 3 it is clear that the efficiency curves for the $45^{\circ}$ and $60^{\circ}$ tilt angles are very close to each other, and they almost overlap in the case where the FEP foil is present.

The IAM was measured in all the different operating conditions and the values of the $p$ exponent are listed in Tab. 1. Despite the scattered values, characterized by a standard deviation of approximately 0.12 for both collectors, the results showed clearly that the presence of the FEP foil reduced the optical properties of the cover, as the HT-A collector had a higher IAM curve than the HT-SA model in every operating condition. On the other hand, tilt angle and flow rate did not appear to influence the IAM in a specific way, so that if a single value of the $p$ exponent needed to be chosen, the simplest approximation would consist in using the 
arithmetic mean, which is equal to 3.9 and 3.6 for the solar collector HT-A and HT-SA respectively.

Tab. 1: Exponent $p$ in the tangent formula of the incidence angle modifier.

\begin{tabular}{|c|c|c|c|}
\hline \multirow{2}{*}{$\begin{array}{c}\text { Tilt angle } \\
{\left[{ }^{\circ}\right]}\end{array}$} & \multirow{2}{*}{$\begin{array}{c}\text { Flow rate } \\
{\left[\text { litres } \mathrm{min}^{-1}\right]}\end{array}$} & \multicolumn{2}{|c|}{$p$ exponent } \\
\hline & & HT-A & HT-SA \\
\hline $45^{\circ}$ & 5 & 4.05 & 3.72 \\
\hline $45^{\circ}$ & 10 & 3.78 & 3.42 \\
\hline $45^{\circ}$ & 25 & 3.73 & 3.68 \\
\hline $60^{\circ}$ & 25 & 3.94 & 3.68 \\
\hline $30^{\circ}$ & 25 & 3.78 & 3.54 \\
\hline \multicolumn{2}{|c|}{ Mean } & 3.85 & 3.61 \\
\hline \multicolumn{2}{|c|}{ Standard deviation } & 0.12 & 0.11 \\
\hline
\end{tabular}

Regarding the pressure drop measurements and the following analysis to calculate the Darcy friction factor, the results of three independent series of tests are represented in Fig. 4. These results show how the friction factor calculated in all the three series of tests presented the same trend, where three different regions can be identified. The first region $(\operatorname{Re}<2000)$ is characterized by a steep decrease of the friction factor as the Reynolds number increases and corresponds to the laminar regime. The second $(2000<\operatorname{Re}<3000)$ represents the transition region and presents a slight increase of the friction factor with the Reynolds number. The third $(R e>3000)$ is the turbulent region and shows again a decreasing trend of the friction factor as function of the Reynolds number, but much less steep than in the laminar regime.

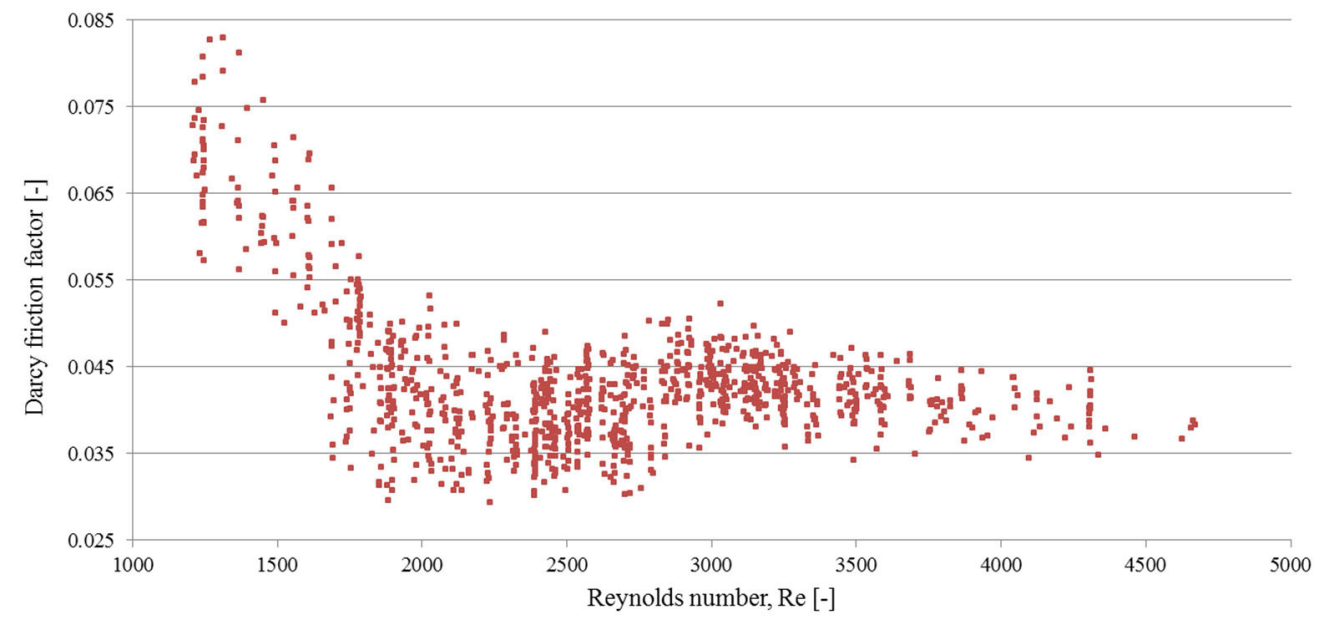

Fig. 4: Calculated Darcy friction factor as function of the Reynolds number in the horizontal pipes of the HT-SA collector.

\subsection{Comparison between experimental efficiency results and Soleff simulation}

The simulation models developed in Soleff were used to evaluate the theoretical efficiency of the two collectors, based on the weather and operation conditions measured during the efficiency tests. The measured and the theoretical efficiency points for the different flow rate and tilt angle conditions are shown in Fig. 5 and Fig. 6. For the sake of clarity, the efficiency points computed by the Soleff models at operating conditions corresponding to Reynolds numbers between 2200 and 2400 are not represented in Fig. 5 and Fig. 6, but are shown independently in Fig. 7.

From Fig. 5 and Fig. 6 it can be noted that the simulation models fit the experimental data points in the laminar $(R e<2000)$ and turbulent regime $(R e>3800)$. The average relative difference between experimental efficiency values and simulated ones is $1 \%$ for both the HT-A and HT-SA collector, while the maximum deviation is equal to $2.2 \%$ for the HT-A model and $1.8 \%$ for the HT-SA model. From the diagrams it is possible to notice that the experimental efficiency points at 5 and 10 (litres $\mathrm{min}^{-1}$ ) are mainly aligned and then could be accurately interpolated by quadratic efficiency curves (see Eq.6-Eq.9). On the other hand, efficiency points obtained for 25 (litres $\mathrm{min}^{-1}$ ) flow rate presented some kind of discontinuity when the ratio $\left(T_{m}-T_{a}\right) / G$ was between 0.044 and $0.051 \mathrm{~K} \mathrm{~m}^{2} \mathrm{~W}^{-1}$. In fact the efficiency values for this temperature level 
were higher than what would be expected from the extrapolated curve fitting the efficiency points obtained for lower values of $\left(T_{m}-T_{a}\right) / G$.

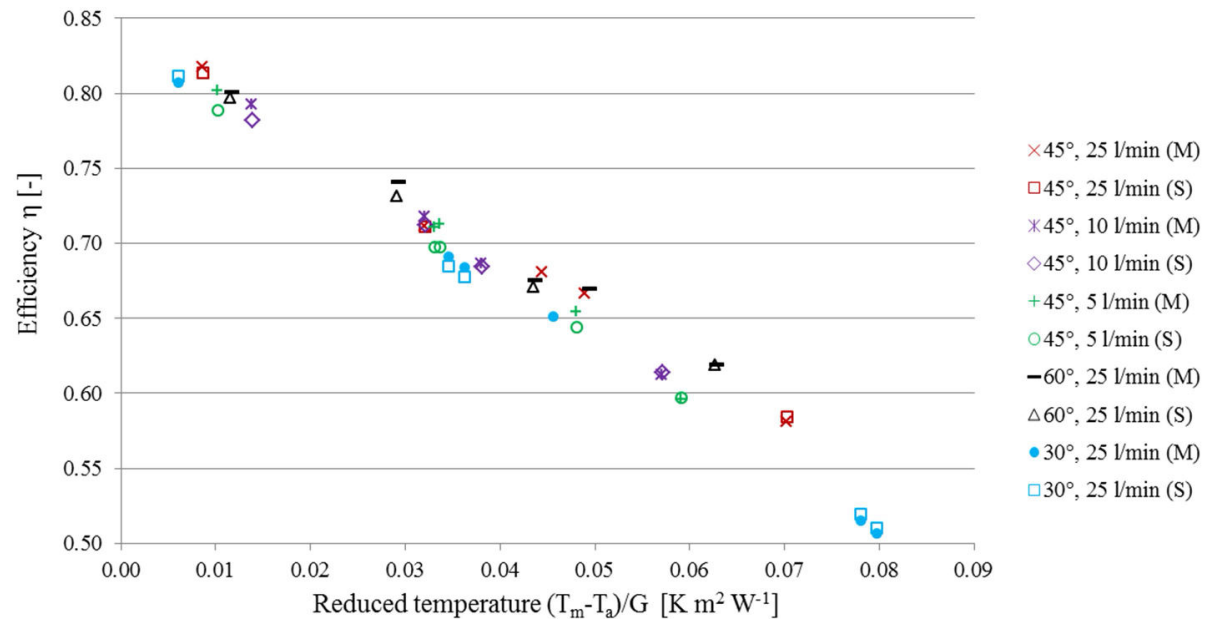

Fig. 5: Comparison between measured (M) and simulated (S) efficiencies of the HT-A collector at different tilts and flow rates.

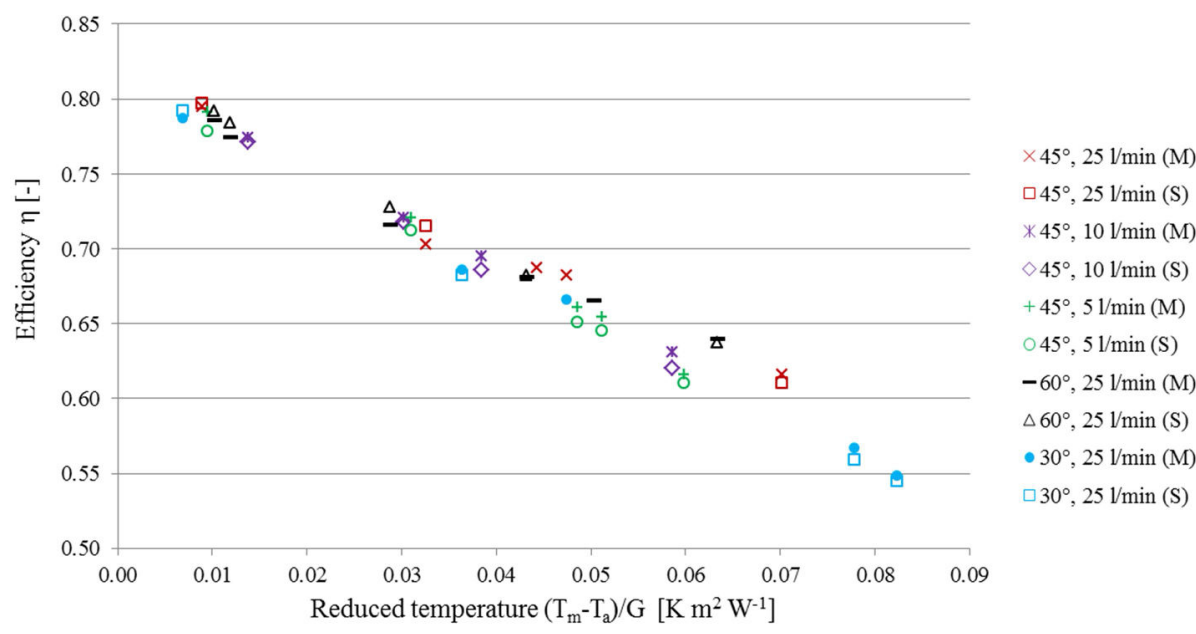

Fig. 6: Comparison between measured (M) and simulated (S) efficiencies of the HT-SA collector at different tilts and flow rates.

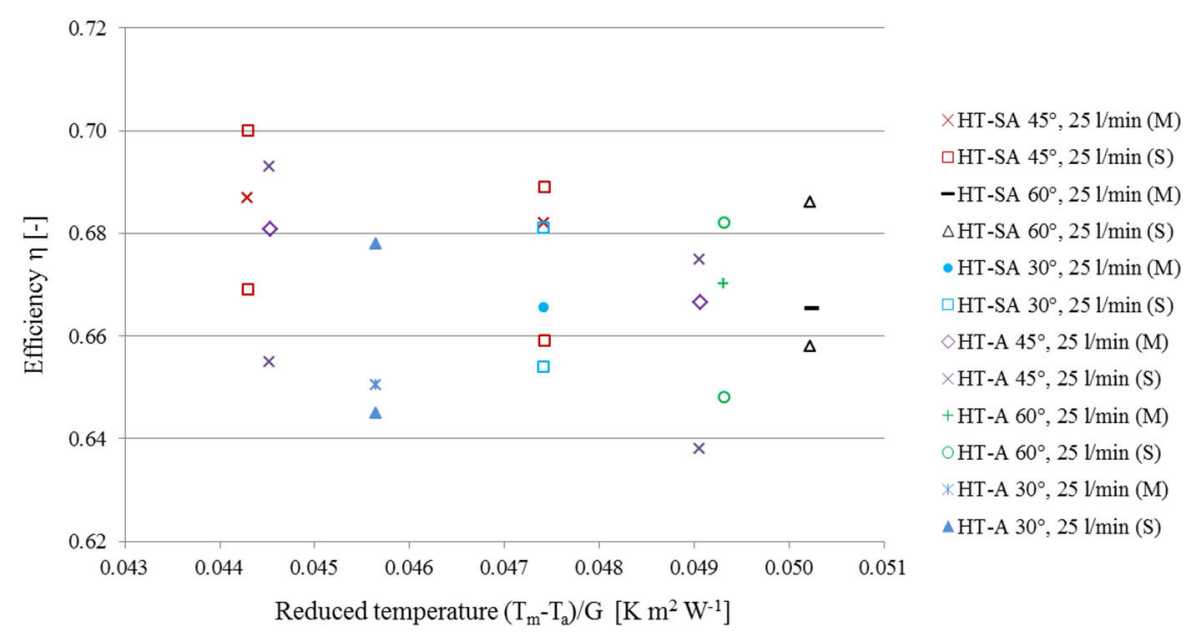

Fig. 7: Comparison between measured (M) and simulated (S) efficiencies of HT-A and HT-SA collector for Reynolds numbers between 2200 and 2400 . In each couple of simulated efficiency points the higher was obtained for turbulent flow and the lower was obtained forcing the Soleff models to assume laminar flow conditions.

In fact, the measured points with a value of the ratio $\left(T_{m}-T_{a}\right) / G$ between 0.044 and $0.051 \mathrm{~K} \mathrm{~m}^{2} \mathrm{~W}^{-1}$ and 25 $\left(\right.$ litres $\mathrm{min}^{-1}$ ) flow rate had Reynolds numbers between 2200 and 2400, which is usually considered to be characterized by transitional flow according to literature (Idelchik, 1994). These efficiency points showed intermediate characteristics between laminar and turbulent regime, both in terms of pressure drop (see Fig. 4) and from the efficiency point of view (Fig. 7). In fact, as can be seen in Fig. 7, the efficiencies measured in 
this range of Reynolds number were always higher than those computed by the Soleff models for laminar flow, but lower than those obtained for turbulent flow.

\section{Discussion}

As can be noted from the experimental efficiency expressions (Eq.5)-(Eq.14), the presence of the FEP foil negatively affected the transmittance of the collector cover, causing a decrease in the initial efficiency as well as a lower IAM curve (Tab. 1). On the other hand, neither the tilt angle nor the fluid flow rate had any major influence on the initial efficiency. So, when supplied with a relatively cold fluid, the HT-A collector performed better than the HT-SA model. However, as the heat losses were lower in the HT-SA collector, the efficiency difference between the two models decreased with increasing mean temperatures until it became null for a certain value of reduced mean temperature, defined as the intersection reduced mean temperature. At this stage, any further increase in temperature entailed a better performance of the HT-SA collector with respect to the HT-A. As the fluid temperature generally increases from relatively low $\left(\sim 40{ }^{\circ} \mathrm{C}\right)$ to relatively high values $\left(\sim 85^{\circ} \mathrm{C}\right)$ along a collector array in a solar heating field, a mixed composition of solar collectors with and without FEP foil seems to be the best solution, using collectors without foil in the first part of the array and collectors with foil in the second part, in order to optimally exploit their different characteristics.

Regarding the effect of the flow rate, the efficiency expressions for 5 and 10 (litres $\mathrm{min}^{-1}$ ) had the usual quadratic form, while those found for a flow rate of 25 (litres $\mathrm{min}^{-1}$ ) were linear. Analysing the single efficiency data points, it was found that the efficiencies measured at the highest temperature level were the main reason for the bending of the curves in the 5 and 10 (litres $\min ^{-1}$ ) cases, while efficiencies calculated at lower temperatures were largely aligned. This result was expected, as heat losses in a solar collector increase more than linearly with the temperature difference between fluid and external environment, due to the radiation contribution, which becomes increasingly important at higher temperatures, the convection losses, which increase due to the lower viscosity of air between absorber and cover, and secondarily the conduction losses, as the thermal conductivity of mineral wool increases with temperature. Conversely, no bending appeared in the diagrams regarding 25 (litres $\mathrm{min}^{-1}$ ) flow rate. The reason of this unexpected behaviour was found in the combination of high fluid velocity and low kinematic viscosity at the highest temperature level, resulting in large Reynolds numbers and turbulent flow regime. This different flow regime led to a much higher heat transfer coefficient than laminar flow and hence was able to counteract the increased thermal losses. If measurements at higher temperature levels had been taken, a quadratic form of the efficiency expression would most likely have been found for 25 (litres $\mathrm{min}^{-1}$ ) flow rate as well. Much attention should be paid when using these linear equations (Eq.10-Eq.15) outside the temperature range for which they were calculated, because extrapolation of the curves for higher values of the ratio $\left(T_{m}-T_{a}\right) / G$ would most likely overestimate the actual efficiency of the collector.

Another consequence of the change in flow regime was the discontinuity in the efficiency curve which could be observed for reduced temperatures between 0.045 and $0.051 \mathrm{~K} \mathrm{~m}^{2} \mathrm{~W}^{-1}$ (Fig. 5 and Fig. 6), which corresponded to Reynolds numbers in the range 2200-2400. Comparison with the results returned by the Soleff models (Fig. 7), pressure drop measurements (Fig. 4) and literature (Idelchick, 1994) proved that the two collectors experienced transitional flow regime along the horizontal pipes in this flow rate and temperature conditions.

Even when no flow regime transition occurs, higher fluid velocities cause better heat transfer between pipe walls and fluid, so that the larger the flow rate, the higher the efficiency (Fig. 2). Additionally, given the same weather conditions, higher flow rates entailed a lower fluid temperature rise across the collector and hence lower losses.

Considering the effect of the tilt angle, Fig. 3 shows that the larger the tilt angle, the higher the efficiency. This trend was in agreement with theory, as both radiation and convection losses are expected to decrease when tilting a flat plate collector. In fact, when a collector is tilted, the view factor of the aperture area toward the earth surface increases, while the view factor toward the sky is reduced. Since the radiation temperature of the sky is lower than that of the earth, a higher tilt positively affects the efficiency by reducing the radiation losses. Convective losses also decrease due to the reduced number of convective cells between the absorber and cover. However, the experimental results show that the efficiency increase was very small when the collectors were tilted from $45^{\circ}$ to larger angles, especially for the model HT-SA. This 
was most likely due to the fact that already at $45^{\circ}$ tilt the FEP foil played a more significant role than the tilt in reducing convection losses. Consequently, a further increase in the tilt did not result in an important enhancement.

The models developed in Soleff proved to be reasonably accurate when the flow regime was either completely laminar $(R e<2000)$ or turbulent $(R e>3800)$, fitting the experimental data with an average error of $1 \%$, while the maximum error was equal to $2.2 \%$ and $1.8 \%$ for the HT-A and HT-SA model respectively. As the results returned by Soleff were compared to experimental measurements in a variety of operating conditions (flow rate, tilt angle and fluid temperature), the models are likely to be able to predict the efficiency of the two collectors with similar degree of accuracy also in other conditions. On the other hand, Soleff was inadequate to simulate the collector efficiency in case of transitional flow, as the software presents a step-change from laminar to turbulent correlations for the convective heat transfer coefficient at a Reynolds number of approximately 2200. Conversely, pressure drop measurements carried out on the HTSA collector showed that the horizontal pipes experienced transition from laminar to turbulent regime in a range of Reynolds number between 2000 and 3000 (Fig. 4). Experimental collector efficiency obtained in the same range of Reynolds numbers were in agreement with these pressure drop measurements, as the collectors presented efficiency values in between those computed by the Soleff models assuming laminar and turbulent regime (Fig. 7). Though, no clear quantitative relation could be found between the theoretical Reynolds number of the flow and the relative position of the experimental efficiency with respect to the two Soleff efficiency points. This means, for example, that an efficiency point characterized by a higher Reynolds number was not necessarily closer to the corresponding Soleff efficiency point obtained for turbulent flow. In fact, transition from laminar to turbulent regime is a process which is not fully understood yet and fluid-dynamic properties of transitional flows are not simply function of the Reynolds number, but are influenced by local irregularities and disturbances.

\section{References}

Arcon Solar A/S, 2010. ARCON solfanger - type HT-SA 35/10.

Chiou, J. P., 1982. The effect of non-uniform fluid flow distribution on the thermal performance of solar collector. Solar Energy 6, 487-502.

Fan, J., Furbo, S., 2008. Buoyancy effects on thermal behavior of a flat-plate solar collector. Journal of Solar Energy Engineering 130.

Furbo, S., Holck, O., 1995. Efficiencies of solar collectors for different tilts. Measurements. Report SR 95-7, Thermal Insulation Laboratory, Technical University of Denmark.

Furbo, S., Perers, B., Bava, F., 2014. Thermal performance of solar district heating plants in Denmark, in EuroSun 2014 Conference Proceedings, Aix-les-Bains, France.

Furbo, S., Shah L.J., 2003. Thermal advantages for solar heating systems with a glass cover with antireflection surfaces. Solar Energy 74, 513-523.

Idelchik, I.E., 1994. Handbook of hydraulic resistance, third ed. CRC press.

Rasmussen, P.B., Svendsen, S., 1996. SolEff Program til beregning af solfangeres effektivitet. Thermal Insulation Laboratory, Technical University of Denmark.

SP Technical Research Institute of Sweden, 2011. Technical Report Ref. PX12871-01.

Wang, X. A., Wu, L. G., 1990. Analysis and performance of flat plate solar collector arrays. Solar Energy 2, 71-78.

Windeleff, J., Nielsen, J.E., 2014. Solar District Heating in Denmark. Danish Energy Authority and PlanEnergi. 